Relations industrielles

Industrial Relations

\title{
Réformes de structure
}

\section{Gérard Dion}

Volume 3, numéro 3, novembre 1947

URI : https://id.erudit.org/iderudit/1023573ar

DOI : https://doi.org/10.7202/1023573ar

Aller au sommaire du numéro

Éditeur(s)

Département des relations industrielles de l'Université Laval

ISSN

0034-379X (imprimé)

1703-8138 (numérique)

Découvrir la revue

Citer cet article

Dion, G. (1947). Réformes de structure. Relations industrielles / Industrial

Relations, 3(3), 33-33. https://doi.org/10.7202/1023573ar

Tous droits réservés @ Département des relations industrielles de l’Université Laval, 1947
Ce document est protégé par la loi sur le droit d'auteur. L'utilisation des services d'Érudit (y compris la reproduction) est assujettie à sa politique d'utilisation que vous pouvez consulter en ligne.

https://apropos.erudit.org/fr/usagers/politique-dutilisation/ 


\section{Bulletin des relations industrielles de la Faculté des sciences sociales de Laval, Québec}

\section{RÉFORMES DE STRUCTURE}

Les événements qui se bousculent depuis la fin de la guerre dans le domaine des relations du travail inquiètent à bon droit tous ceux qui recherchent sincèrement la paix et l'ordre dans notre pays. Mais si tragiques que soicnt les conflits et les grèves qui surgissent entre patrons et ouvriers avec les discussions qu'ils provoquent, les passions qu'ils excitent et les conséquences économiques qu'ils entraînent, ils ne sauraient nous faire oublier qu'au fond de ce désarroi dans les esprits et de ce désordre dans les faits, il y a d'autres questions plus sérieuses, plus importantes qui réclament une étude approfondie, des données sûres et qui nous permettront peut-être de découvrir de vraies et durables solutions. Sans négliger de pourvoir aux mesures accidentelles que les circonstances imposent, c'est aux principes qu'il faut viser; il ne suffit pas, en effet, de remédier en détail à quelques maux, quand c'est tout l'organisme social qu'il faut examiner et guérir. II y a déjà seize ans que le Pape Pie XI, précisant la pensée de ses prédécesseurs, a lancé ce mot d'ordre: «Réforme des moeurs, réforme des institutions 》.

Dans le présent numéro du Bulletin, nous abordons donc ce problème si important des réformes de structure. On y trouvera un article substantiel, écrit par un théologien de valeur doublé d'un sociologue averti, monsieur Paul-Emile Bolté, p.s.s., professeur à la Faculté de Théologie de l'Université de Montréal et ancien élève de notre Faculté. Dans le domaine économique, les réformes de structure se posent sur le plan de l'entreprise, de la profession et de la société civile. Elles ont pour base le problème de la propriété et de sa distribution sous toutes ses formes. Cependant, on ne peut oublier non plus que l'enjeu du conflit entre les patrons et les ouvriers n'est pas seulement une questions de piastres et de cents, mais une répartition nouvelle de l'autorité et une reconnaissance pratique de la dignité humaine. Voilà pourquoi nous avons l'intention, sans courir à l'aventure dans les fossés de gauche et de droite, mais en nous basant sur la doctrine sociale de l'Eglise, qui est assez féconde par elle-même, et sur les réalités sociales telles qu'elles se présentent chez nous, de repenser les conceptions que l'on se fait des régimes de la propriété, de l'entreprise, du capitalisme, du profit, de l'autorité dans les relations du travail, de la participation à la propriété, à la gestion et au profit de l'entreprise.

Dans les faits, on a déjà pris une certaine attitude pratique. Depuis la guerre, le gouvernement fédéral pousse de l'avant les comités mixtes de production. Les travailleurs, en général, si on excepte certains de leurs chefs, ressentent de façon plutôt indéfinie mais non moins réelle le besoin de réformes de structure. Quelques employeurs, de leur côté, sans toujours se rendre compte entièrement de l'incidence à long terme de certaines réformes fragmentaires qu'ils opèrent et parfois encore moins des principes qui y sont impliqués ont déjà en quelques endroits réalisé ce que l’on appelle le salaire annuel garanti, des «multiple-management plans » et une participation aux profits ou à la propriété des entreprises.

Dans le domaine économique et social, malgré les déclarations grandiloquentes et démagogiques de certains idéalistes, il n'y a pas à proprement parler de révolution, si l'on entend par ce mot des changements brusques. L'histoire nous enseigne que l'on a souvent changé d'appellation le nom des choses et remplacé des personnes, mais ce n'est qu'une évolution lente qui s'est produite. Quand nous parlons de réforme de structure, nous nous lançons donc dans un travail à longue portée. Il se peut que les nécessités présentes, la psychologie populaire, le degré de préparation des hommes obligent les travailleurs sociaux à retarder l'exécution d'une mesure, mais jamais ils ne doivent perdre de vue l'ensemble pour s'attacher à des détails qui, malgré l'importance qu'ils possèdent, demeurent toujours des détails. Pour cela, ils ont besoin de connaître aussi parfaitement que possible les principes qui doivent orienter leur action et les faits auxquels ils s'appliquent. Le succès d'une véritable réforme de structure en dépend. 